\title{
Modified Hybrid Block Iterative Algorithm for Convex Feasibility Problems and Generalized Equilibrium Problems for Uniformly Quasi- $\phi$-Asymptotically Nonexpansive Mappings
}

\author{
Siwaporn Saewan and Poom Kumam \\ Department of Mathematics, Faculty of Science, King Mongkut's University of Technology Thonburi \\ (KMUTT), Bangmod, Bangkok 10140, Thailand
}

Correspondence should be addressed to Poom Kumam, poom.kum@kmutt.ac.th

Received 14 May 2010; Revised 16 June 2010; Accepted 21 June 2010

Academic Editor: W. A. Kirk

Copyright (C) 2010 S. Saewan and P. Kumam. This is an open access article distributed under the Creative Commons Attribution License, which permits unrestricted use, distribution, and reproduction in any medium, provided the original work is properly cited.

\begin{abstract}
We introduce a modified block hybrid projection algorithm for solving the convex feasibility problems for an infinite family of closed and uniformly quasi- $\phi$-asymptotically nonexpansive mappings and the set of solutions of the generalized equilibrium problems. We obtain a strong convergence theorem for the sequences generated by this process in a uniformly smooth and strictly convex Banach space with Kadec-Klee property. The results presented in this paper improve and extend some recent results.
\end{abstract}

\section{Introduction and Preliminaries}

The convex feasibility problem (CFP) is the problem of computing points laying in the intersection of a finite family of closed convex subsets $C_{j}, j=1,2, \ldots, N$, of a Banach space $E$. This problem appears in various fields of applied mathematics. The theory of optimization [1], Image Reconstruction from projections [2], and Game Theory [3] are some examples. There is a considerable investigation on (CFP) in the framework of Hilbert spaces which captures applications in various disciplines such as image restoration, computer tomograph, and radiation therapy treatment planning [4]. The advantage of a Hilbert space $H$ is that the projection $P_{C}$ onto a closed convex subset $C$ of $H$ is nonexpansive. So projection methods have dominated in the iterative approaches to (CFP) in Hilbert spaces. In 1993, Kitahara and Takahashi [5] deal with the convex feasibility problem by convex combinations of sunny nonexpansive retractions in a uniformly convex Banach space. It is known that if $C$ 
is a nonempty closed convex subset of a smooth, reflexive, and strictly convex Banach space, then the generalized projection (see, Alber [6] or Kamimura and Takahashi [7]) from E onto $C$ is relatively nonexpansive, whereas the metric projection from $H$ onto $C$ is not generally nonexpansive.

We note that the block iterative method is a method which is often used by many authors to solve the convex feasibility problem (CFP) (see, [8, 9], etc.). In 2008, Plubtieng and Ungchittrakool [10] established strong convergence theorems of block iterative methods for a finite family of relatively nonexpansive mappings in a Banach space by using the hybrid method in mathematical programming.

Let $C$ be a nonempty closed convex subset of a real Banach space $E$ with $\|\cdot\|$ and $E^{*}$ being the dual space of $E$. Let $f$ be a bifunction of $C \times C$ into $\mathbb{R}$ and $B: C \rightarrow E^{*}$ a monotone mapping. The generalized equilibrium problem, denoted by GEP, is to find $x \in C$ such that

$$
f(x, y)+\langle B x, y-x\rangle \geq 0, \quad \forall y \in C .
$$

The set of solutions for the problem (1.1) is denoted by $\operatorname{GEP}(f, B)$, that is

$$
\operatorname{GEP}(f, B):=\{x \in C: f(x, y)+\langle B x, y-x\rangle \geq 0, \forall y \in C\}
$$

If $B \equiv 0$, the problem (1.1) reducing into the equilibrium problem for $f$, denoted by $\operatorname{EP}(f)$, is to find $x \in C$ such that

$$
f(x, y) \geq 0, \quad \forall y \in C
$$

If $f \equiv 0$, the problem (1.1) reducing into the classical variational inequality, denoted by $\operatorname{VI}(B, C)$, is to find $x^{*} \in C$ such that

$$
\left\langle B x^{*}, y-x^{*}\right\rangle \geq 0, \quad \forall y \in C \text {. }
$$

The above formulation (1.3) was shown in [11] to cover monotone inclusion problems, saddle point problems, variational inequality problems, minimization problems, optimization problems, variational inequality problems, vector equilibrium problems, and Nash equilibria in noncooperative games. In addition, there are several other problems, for example, the complementarity problem, fixed point problem, and optimization problem, which can also be written in the form of an $\mathrm{EP}(f)$. In other words, the $\mathrm{EP}(f)$ is a unifying model for several problems arising in physics, engineering, science, optimization, economics, and so forth. In the last two decades, many papers have appeared in the literature on the existence of solutions of $\mathrm{EP}(f)$; see, for example [11] and references therein. Some solution methods have been proposed to solve the $\mathrm{EP}(f)$; see, for example, [12-29] and references therein.

Consider the functional defined by

$$
\phi(x, y)=\|x\|^{2}-2\langle x, J y\rangle+\|y\|^{2}, \quad \forall x, y \in E,
$$


where $J$ is the duality mapping from $E$ into $E^{*}$. It is well known that if $C$ is a nonempty closed convex subset of a Hilbert space $H$ and $P_{C}: H \rightarrow C$ is the metric projection of $H$ onto $C$, then $P_{C}$ is nonexpansive. This fact actually characterizes Hilbert spaces and consequently, it is not available in more general Banach spaces. It is obvious from the definition of function $\phi$ that

$$
(\|x\|-\|y\|)^{2} \leq \phi(x, y) \leq(\|x\|+\|y\|)^{2}, \quad \forall x, y \in E .
$$

If $E$ is a Hilbert space, then $\phi(x, y)=\|x-y\|^{2}$, for all $x, y \in E$. On the other hand, the generalized projection (Alber [6]) $\Pi_{C}: E \rightarrow C$ is a map that assigns to an arbitrary point $x \in E$ the minimum point of the functional $\phi(x, y)$, that is, $\Pi_{C} x=\bar{x}$, where $\bar{x}$ is the solution to the minimization problem

$$
\phi(\bar{x}, x)=\inf _{y \in C} \phi(y, x)
$$

and existence and uniqueness of the operator $\Pi_{C}$ follow from the properties of the functional $\phi(x, y)$ and strict monotonicity of the mapping $J$ (see, for example, $[6,7,30-32]$ ).

Remark 1.1. If $E$ is a reflexive, strictly convex and smooth Banach space, then for $x, y \in E$, $\phi(x, y)=0$ if and only if $x=y$. It is sufficient to show that if $\phi(x, y)=0$ then $x=y$. From (1.5), we have $\|x\|=\|y\|$. This implies that $\langle x, J y\rangle=\|x\|^{2}=\|J y\|^{2}$. From the definition of $J$, one has $J x=J y$. Therefore, we have $x=y$; see [31,32] for more details.

Let $C$ be a closed convex subset of $E$; a mapping $T: C \rightarrow C$ is said to be nonexpansive if $\|T x-T y\| \leq\|x-y\|$, for all $x, y \in C$. A point $x \in C$ is a fixed point of $T$ provided $T x=x$. Denote by $F(T)$ the set of fixed points of $T$; that is, $F(T)=\{x \in C: T x=x\}$. Recall that a point $p$ in $C$ is said to be an asymptotic fixed point of $T$ [33] if $C$ contains a sequence $\left\{x_{n}\right\}$ which converges weakly to $p$ such that $\lim _{n \rightarrow \infty}\left\|x_{n}-T x_{n}\right\|=0$. The set of asymptotic fixed points of $T$ will be denoted by $\widetilde{F(T)}$.

A mapping $T$ from $C$ into itself is said to be relatively nonexpansive [34-36] if $\widetilde{F(T)}=F(T)$ and $\phi(p, T x) \leq \phi(p, x)$ for all $x \in C$ and $p \in F(T)$. The asymptotic behavior of a relatively nonexpansive mapping was studied in [37-39]. $T$ is said to be $\phi$-nonexpansive, if $\phi(T x, T y) \leq \phi(x, y)$ for $x, y \in C$. T is said to be relatively quasi-nonexpansive if $F(T) \neq \emptyset$ and $\phi(p, T x) \leq \phi(p, x)$ for all $x \in C$ and $p \in F(T)$. T is said to be quasi- $\phi$-asymptotically nonexpansive if $F(T) \neq \emptyset$ and there exists a real sequence $\left\{k_{n}\right\} \subset[1, \infty)$ with $k_{n} \rightarrow 1$ such that $\phi\left(p, T^{n} x\right) \leq k_{n} \phi(p, x)$ for all $n \geq 1 x \in C$ and $p \in F(T)$. A mapping $T$ is said to be closed if for any sequence $\left\{x_{n}\right\} \subset C$ with $x_{n} \rightarrow x$ and $T x_{n} \rightarrow y, T x=y$. It is easy to know that each relatively nonexpansive mapping is closed. The class of quasi- $\phi$-asymptotically nonexpansive mappings contains properly the class of quasi- $\phi$-nonexpansive mappings as a subclass and the class of quasi- $\phi$-nonexpansive mappings contains properly the class of relatively nonexpansive mappings as a subclass, but the converse may be not true (see more details [37-41]).

A Banach space $E$ is said to be strictly convex if $\|(x+y) / 2\|<1$ for all $x, y \in E$ with $\|x\|=\|y\|=1$ and $x \neq y$. Let $U=\{x \in E:\|x\|=1\}$ be the unit sphere of $E$. Then a Banach space $E$ is said to be smooth if the $\operatorname{limit}_{t \rightarrow 0}(\|x+t y\|-\|x\|) / t$ exists for each 
$x, y \in U$. It is also said to be uniformly smooth if the limit is attained uniformly for $x, y \in U$. Let $E$ be a Banach space. The modulus of convexity of $E$ is the function $\delta:[0,2] \rightarrow[0,1]$ defined by $\delta(\varepsilon)=\inf \{1-\|(x+y) / 2\|: x, y \in E,\|x\|=\|y\|=1,\|x-y\| \geq \varepsilon\}$. A Banach space $E$ is uniformly convex if and only if $\delta(\varepsilon)>0$ for all $\varepsilon \in(0,2]$. Let $p$ be a fixed real number with $p \geq 2$. A Banach space $E$ is said to be $p$-uniformly convex if there exists a constant $c>0$ such that $\delta(\varepsilon) \geq c \varepsilon^{p}$ for all $\varepsilon \in[0,2]$; see [42] for more details. Observe that every $p$-uniform convex is uniformly convex. One should note that no Banach space is $p$ uniform convex for $1<p<2$. It is well known that a Hilbert space is 2-uniformly convex, uniformly smooth. For each $p>1$, the generalized duality mapping $J_{p}: E \rightarrow 2^{E^{*}}$ is defined by $J_{p}(x)=\left\{x^{*} \in E^{*}:\left\langle x, x^{*}\right\rangle=\|x\|^{p},\left\|x^{*}\right\|=\|x\|^{p-1}\right\}$ for all $x \in E$. In particular, $J=J_{2}$ is called the normalized duality mapping. If $E$ is a Hilbert space, then $J=I$, where $I$ is the identity mapping. It is also known that if $E$ is uniformly smooth, then $J$ is uniformly norm-to-norm continuous on each bounded subset of $E$.

The following basic properties can be found in Cioranescu [31].

(i) If $E$ is a uniformly smooth Banach space, then $J$ is uniformly continuous on each bounded subset of $E$.

(ii) If $E$ is a reflexive and strictly convex Banach space, then $J^{-1}$ is norm-weak*continuous.

(iii) If $E$ is a smooth, strictly convex, and reflexive Banach space, then the normalized duality mapping $J: E \rightarrow 2^{E^{*}}$ is single-valued, one-to-one, and onto.

(iv) A Banach space $E$ is uniformly smooth if and only if $E^{*}$ is uniformly convex.

(v) Each uniformly convex Banach space $E$ has the Kadec-Klee property, that is, for any sequence $\left\{x_{n}\right\} \subset E$, if $x_{n} \rightarrow x \in E$ and $\left\|x_{n}\right\| \rightarrow\|x\|, x_{n} \rightarrow x$.

In 2005, Matsushita and Takahashi [40] proposed the following hybrid iteration method (it is also called the CQ method) with generalized projection for relatively nonexpansive mapping $T$ in a Banach space $E$ :

$$
\begin{gathered}
x_{0} \in C \text { chosen arbitrarily, } \\
y_{n}=J^{-1}\left(\alpha_{n} J x_{n}+\left(1-\alpha_{n}\right) J T x_{n}\right), \\
C_{n}=\left\{z \in C: \phi\left(z, y_{n}\right) \leq \phi\left(z, x_{n}\right)\right\}, \\
Q_{n}=\left\{z \in C:\left\langle x_{n}-z, J x_{0}-J x_{n}\right\rangle \geq 0\right\}, \\
x_{n+1}=\Pi_{C_{n} \cap Q_{n}} x_{0} .
\end{gathered}
$$

They proved that $\left\{x_{n}\right\}$ converges strongly to $\Pi_{F(T)} x_{0}$, where $\Pi_{F(T)}$ is the generalized projection from $C$ onto $F(T)$. In 2007, Plubtieng and Ungchittrakool [43] generalized the processes (1.8) to the new general processes of two relatively nonexpansive mappings in a Banach space. Let $C$ be a closed convex subset of a Banach space $E$ and $S, T: C \rightarrow C$ 
relatively nonexpansive mappings such that $F:=F(S) \cap F(T) \neq \emptyset$. Define $\left\{x_{n}\right\}$ in the following way:

$$
\begin{gathered}
x_{0}=x \in C, \\
y_{n}=J^{-1}\left(\alpha_{n} J x_{n}+\left(1-\alpha_{n}\right) J z_{n}\right), \\
z_{n}=J^{-1}\left(\beta_{n}^{(1)} J x_{n}+\beta_{n}^{(2)} J T x_{n}+\beta_{n}^{(3)} J S x_{n}\right), \\
H_{n}=\left\{z \in C: \phi\left(z, y_{n}\right) \leqslant \phi\left(z, x_{n}\right)\right\}, \\
W_{n}=\left\{z \in C:\left\langle x_{n}-z, J x-J x_{n}\right\rangle \geqslant 0\right\}, \\
x_{n+1}=P_{H_{n} \cap W_{n}} x, \quad n=0,1,2, \ldots,
\end{gathered}
$$

where $\left\{\alpha_{n}\right\},\left\{\beta_{n}^{(1)}\right\},\left\{\beta_{n}^{(2)}\right\}$, and $\left\{\beta_{n}^{(3)}\right\}$ are sequences in $[0,1]$ with $\beta_{n}^{(1)}+\beta_{n}^{(2)}+\beta_{n}^{(3)}=1$ for all $n \in \mathbb{N} \cup\{0\}$.

In 2009, Qin et al. [26] introduced a hybrid projection algorithm to find a common element of the set of solutions of an equilibrium problem and the set of common fixed points of two quasi- $\phi$-nonexpansive mappings in the framework of Banach spaces:

$$
\begin{gathered}
x_{0}=x \text { chosen arbitrarily, } \\
C_{1}=C, \\
x_{1}=\prod_{C_{1}} x_{0}, \\
y_{n}=J^{-1}\left(\alpha_{n} J x_{n}+\beta_{n} J T x_{n}+\gamma_{n} J S x_{n}\right), \\
u_{n} \in C \text { such that } f\left(u_{n}, y\right)+\frac{1}{r_{n}}\left\langle y-u_{n} J u_{n}-J y_{n}\right\rangle \geq 0, \quad \forall y \in C, \\
C_{n+1}=\left\{z \in C_{n}: \phi\left(z, u_{n}\right) \leq \phi\left(z, x_{n}\right)\right\}, \\
x_{n+1}=\prod_{C_{n+1}} x_{0},
\end{gathered}
$$

where $\Pi_{C_{n+1}}$ is the generalized projection from $E$ onto $C_{n+1}$. They proved that the sequence $\left\{x_{n}\right\}$ converges strongly to $\Pi_{F(T) \cap F(S) \cap E P(f)} x_{0}$. In the same year, Wattanawitoon and Kumam [44] and Petrot et al. [45] using the idea of Takahashi and Zembayashi [46, 47] and Plubtieng and Ungchittrakool [43] extend the notion from relatively nonexpansive mappings or quasi$\phi$-nonexpansive mappings to two relatively quasi-nonexpansive mappings and also proved some strong convergence theorems to approximate a common fixed point of relatively quasinonexpansive mappings and the set of solutions of an equilibrium problem in the framework of Banach spaces. In 2010, Chang et al. [48] proposed the modified block iterative algorithm for solving the convex feasibility problems for an infinite family of closed and uniformly quasi- $\phi$-asymptotically nonexpansive mapping; they obtain the strong convergence theorems in a Banach space. Recently, many authors considered the iterative methods for finding a common element of the set of solutions to the problem (1.3) and of the set of fixed points of nonexpansive mappings; see, for instance, [12-27] and the references therein. 
Motivated by Chang et al. [48], Qin et al. [26, 49], Wattanawitoon and Kumam [44], Petrot et al. [45], Zegeye [50], and other recent works, in this paper we introduce a new modified block hybrid projection algorithm for finding a common element of the set of solutions of the generalized equilibrium problems and the set of common fixed points of an infinite family of closed and uniformly quasi- $\phi$-asymptotically nonexpansive mappings which is more general than closed quasi- $\phi$-nonexpansive mappings in a uniformly smooth and strictly convex Banach space $E$ with Kadec-Klee property. The results presented in this paper improve and generalize some well-known results in the literature.

\section{Basic Results}

We also need the following lemmas for the proof of our main results.

Lemma 2.1 (Kamimura and Takahashi [7]). Let E be a uniformly convex and smooth Banach space and let $\left\{x_{n}\right\}$ and $\left\{y_{n}\right\}$ be two sequences of $E$. If $\phi\left(x_{n}, y_{n}\right) \rightarrow 0$ and either $\left\{x_{n}\right\}$ or $\left\{y_{n}\right\}$ is bounded, then $\left\|x_{n}-y_{n}\right\| \rightarrow 0$.

Lemma 2.2 (Alber [6]). Let $C$ be a nonempty closed convex subset of a smooth Banach space $E$ and $x \in E$. Then $x_{0}=\Pi_{C} x$ if and only if

$$
\left\langle x_{0}-y_{1} J x-J x_{0}\right\rangle \geq 0, \quad \forall y \in C
$$

Lemma 2.3 (Alber [6]). Let E be a reflexive, strictly convex and smooth Banach space, let $C$ be a nonempty closed convex subset of $E$, and let $x \in E$. Then

$$
\phi\left(y, \Pi_{C} x\right)+\phi\left(\Pi_{C} x, x\right) \leq \phi(y, x), \quad \forall y \in C .
$$

For solving the equilibrium problem for a bifunction $f: C \times C \rightarrow \mathbb{R}$, let us assume that $f$ satisfies the following conditions:

(A1) $f(x, x)=0$ for all $x \in C$;

(A2) $f$ is monotone, that is, $f(x, y)+f(y, x) \leq 0$ for all $x, y \in C$;

(A3) for each $x, y, z \in C$,

$$
\lim _{t \downarrow 0} f(t z+(1-t) x, y) \leq f(x, y)
$$

(A4) for each $x \in C, y \mapsto f(x, y)$ is convex and lower semicontinuous.

Lemma 2.4 (Blum and Oettli [11]). Let $C$ be a closed convex subset of a smooth, strictly convex and reflexive Banach space $E$, let $f$ be a bifunction from $C \times C$ to $\mathbb{R}$ satisfying $(A 1)-(A 4)$, and let $r>0$ and $x \in E$. Then there exists $z \in C$ such that

$$
f(z, y)+\frac{1}{r}\langle y-z, J z-J x\rangle \geq 0, \quad \forall y \in C
$$


Lemma 2.5 (Zegeye [50]). Let $C$ be a closed convex subset of a uniformly smooth, strictly convex and reflexive Banach space $E$ and let $f$ be a bifunction from $C \times C$ to $\mathbb{R}$ satisfying $(A 1)-(A 4)$ and let $B$ be a monotone mapping from $C$ into $E^{*}$. For $r>0$ and $x \in E$, define a mapping $T_{r}: C \rightarrow C$ as follows:

$$
T_{r} x=\left\{z \in C: f(z, y)+\langle B x, y-z\rangle+\frac{1}{r}\langle y-z, J z-J x\rangle \geq 0, \forall y \in C\right\}
$$

for all $x \in C$. Then the following hold:

(1) $T_{r}$ is single-valued;

(2) $T_{r}$ is a firmly nonexpansive-type mapping, for all $x, y \in E$,

$$
\left\langle T_{r} x-T_{r} y, J T_{r} x-J T_{r} y\right\rangle \leq\left\langle T_{r} x-T_{r} y, J x-J y\right\rangle
$$

(3) $F\left(T_{r}\right)=G E P(f, B)$;

(4) $\operatorname{GEP}(f, B)$ is closed and convex.

Lemma 2.6 (Zegeye [50]). (Let $C$ be a closed convex subset of a smooth, strictly convex, and reflexive Banach space $E$, let $f$ be a bifunction from $C \times C$ to $\mathbb{R}$ satisfying $(A 1)-(A 4)$, and let $B$ be a monotone mapping from $C$ into $E^{*}$. For $r>0, x \in E$, and $q \in F\left(T_{r}\right)$, we have that

$$
\phi\left(q, T_{r} x\right)+\phi\left(T_{r} x, x\right) \leq \phi(q, x)
$$

Lemma 2.7 (Chang et al. [48]). Let $E$ be a uniformly convex Banach space, $r>0$ a positive number, and $B_{r}(0)$ a closed ball of $E$. Then, for any given sequence $\left\{x_{i}\right\}_{i=1}^{\infty} \subset B_{r}(0)$ and for any given sequence $\left\{\lambda_{i}\right\}_{i=1}^{\infty}$ of positive number with $\sum_{n=1}^{\infty} \lambda_{n}=1$, there exists a continuous, strictly increasing, and convex function $g:[0,2 r) \rightarrow[0, \infty)$ with $g(0)=0$ such that, for any positive integer $i, j$ with $i<j$,

$$
\left\|\sum_{n=1}^{\infty} \lambda_{n} x_{n}\right\|^{2} \leq \sum_{n=1}^{\infty} \lambda_{n}\left\|x_{n}\right\|^{2}-\lambda_{i} \lambda_{j} g\left(\left\|x_{i}-x_{j}\right\|\right) .
$$

Lemma 2.8 (Chang et al. [48]). Let E be a real uniformly smooth and strictly convex Banach space, and $C$ a nonempty closed convex subset of $E$. Let $T: C \rightarrow C$ be a closed and quasi- $\phi$-asymptotically nonexpansive mapping with a sequence $\left\{k_{n}\right\} \subset[1, \infty), k_{n} \rightarrow 1$. Then $F(T)$ is a closed convex subset of $C$.

Definition 2.9 (Chang et al. [48]). (1) Let $\left\{S_{i}\right\}_{i=1}^{\infty}: C \rightarrow C$ be a sequence of mapping. $\left\{S_{i}\right\}_{i=1}^{\infty}$ is said to be a family of uniformly quasi- $\phi$-asymptotically nonexpansive mappings, if $\cap_{n=1}^{\infty} F\left(S_{n}\right) \neq \emptyset$, and there exists a sequence $\left\{k_{n}\right\} \subset[1, \infty)$ with $k_{n} \rightarrow 1$ such that for each $i \geq 1$,

$$
\phi\left(p, S_{i}^{n} x\right) \leq k_{n} \phi(p, x), \quad \forall p \in \bigcap_{n=1}^{\infty} F\left(S_{n}\right), x \in C, \forall n \geq 1
$$


(2) A mapping $S: C \rightarrow C$ is said to be uniformly $L$-Lipschitz continuous if there exists a constant $L>0$ such that

$$
\left\|S^{n} x-S^{n} y\right\| \leq L\|x-y\|, \quad \forall x, y \in C .
$$

\section{Main Results}

In this section, we prove the new convergence theorems for finding the set of solutions of a general equilibrium problems and the common fixed point set of a family of closed and uniformly quasi- $\phi$-asymptotically nonexpansive mappings in a uniformly smooth and strictly convex Banach space $E$ with Kadec-Klee property.

Theorem 3.1. Let $C$ be a nonempty closed and convex subset of a uniformly smooth and strictly convex Banach space $E$ with Kadec-Klee property. Let $f$ be a bifunction from $C \times C$ to $\mathbb{R}$ satisfying $(A 1)-(A 4)$. Let $B$ be a continuous monotone mapping of $C$ into $E^{*}$. Let $\left\{S_{i}\right\}_{i=1}^{\infty}: C \rightarrow C$ be an infinite family of closed uniformly $L_{i}$-Lipschitz continuous and uniformly quasi- $\phi$-asymptotically nonexpansive mappings with a sequence $\left\{k_{n}\right\} \subset[1, \infty), k_{n} \rightarrow 1$ such that $F:=\cap_{i=1}^{\infty} F\left(S_{i}\right) \cap$ $\operatorname{GEP}(f, B)$ is a nonempty and bounded subset in C. For an initial point $x_{0} \in E$ with $x_{1}=\Pi_{C_{1}} x_{0}$ and $C_{1}=C$, we define the sequence $\left\{x_{n}\right\}$ as follows:

$$
\begin{gathered}
y_{n}=J^{-1}\left(\beta_{n} J x_{n}+\left(1-\beta_{n}\right) J z_{n}\right), \\
z_{n}=J^{-1}\left(\alpha_{n, 0} J x_{n}+\sum_{i=1}^{\infty} \alpha_{n, i} J S_{i}^{n} x_{n}\right), \\
u_{n} \in C \text { such that } f\left(u_{n}, y\right)+\left\langle B y_{n}, y-u_{n}\right\rangle+\frac{1}{r_{n}}\left\langle y-u_{n}, J u_{n}-J y_{n}\right\rangle \geq 0, \quad \forall y \in C, \\
C_{n+1}=\left\{z \in C_{n}: \phi\left(z, u_{n}\right) \leq \phi\left(z, x_{n}\right)+\theta_{n}\right\}, \\
x_{n+1}=\prod_{C_{n+1}} x_{0}, \quad \forall n \geq 0,
\end{gathered}
$$

where $J$ is the duality mapping on $E, \theta_{n}=\sup _{q \in F}\left(k_{n}-1\right) \phi\left(q, x_{n}\right),\left\{\alpha_{n, i}\right\},\left\{\beta_{n}\right\}$ are sequences in $[0,1]$ and $\left\{r_{n}\right\} \subset[a, \infty)$ for some $a>0$. If $\sum_{i=0}^{\infty} \alpha_{n, i}=1$ for all $n \geq 0$ and $\lim _{i n f_{n \rightarrow \infty}} \alpha_{n, 0} \alpha_{n, i}>0$ for all $i \geq 1$, then $\left\{x_{n}\right\}$ converges strongly to $p \in F$, where $p=\Pi_{F} x_{0}$.

Proof. We first show that $C_{n+1}$ is closed and convex for each $n \geq 0$. Clearly $C_{1}=C$ is closed and convex. Suppose that $C_{n}$ is closed and convex for each $n \in \mathbb{N}$. Since for any $z \in C_{n}$, we know

$$
\phi\left(z, u_{n}\right) \leq \phi\left(z, x_{n}\right)+\theta_{n} \Longleftrightarrow 2\left\langle z, J x_{n}-J u_{n}\right\rangle \leq\left\|x_{n}\right\|^{2}-\left\|u_{n}\right\|^{2}+\theta_{n} .
$$

So, $C_{n+1}$ is closed and convex. Therefore, $\Pi_{F} x_{0}$ and $\Pi_{C_{n}} x_{0}$ are well defined. Next, we show that $F \subset C_{n}$ for all $n \geq 0$. Indeed, put $u_{n}=T_{r_{n}} y_{n}$ for all $n \geq 0$. It is clear that $F_{1} \subset C_{1}=C$. 
Suppose $F \subset C_{n}$ for $n \in \mathbb{N}$, by the convexity of $\|\cdot\|^{2}$, property of $\phi$, Lemma 2.7, and uniformly quasi- $\phi$-asymptotically nonexpansive of $S_{n}$ for each $q \in F \subset C_{n}$, we observed that

$$
\begin{aligned}
\phi\left(q, u_{n}\right) & =\phi\left(q, T_{r_{n}} y_{n}\right) \\
\leq & \phi\left(q, y_{n}\right) \\
& =\phi\left(q, J^{-1}\left(\beta_{n} J x_{n}+\left(1-\beta_{n}\right) J z_{n}\right)\right. \\
& =\|q\|^{2}-2\left\langle q, \beta_{n} J x_{n}+\left(1-\beta_{n}\right) J z_{n}\right\rangle+\left\|\beta_{n} J x_{n}+\left(1-\beta_{n}\right) J z_{n}\right\|^{2} \\
& \leq\|q\|^{2}-2 \beta_{n}\left\langle q, J x_{n}\right\rangle-2\left(1-\beta_{n}\right)\left\langle q, J z_{n}\right\rangle+\beta_{n}\left\|x_{n}\right\|^{2}+\left(1-\beta_{n}\right)\left\|z_{n}\right\|^{2} \\
& =\beta_{n} \phi\left(q, x_{n}\right)+\left(1-\beta_{n}\right) \phi\left(q, z_{n}\right)
\end{aligned}
$$

and

$$
\begin{aligned}
\phi\left(q, z_{n}\right)= & \phi\left(q, J^{-1}\left(\alpha_{n, 0} J x_{n}+\sum_{i=1}^{\infty} \alpha_{n, i} J S_{i}^{n} x_{n}\right)\right) \\
= & \|q\|^{2}-2\left\langle q, \alpha_{n, 0} J x_{n}+\sum_{i=1}^{\infty} \alpha_{n, i} J S_{i}^{n} x_{n}\right\rangle+\left\|\alpha_{n, 0} J x_{n}+\sum_{i=1}^{\infty} \alpha_{n, i} J S_{i}^{n} x_{n}\right\|^{2} \\
\leq & \|q\|^{2}-2 \alpha_{n, 0}\left\langle q, J x_{n}\right\rangle-2 \sum_{i=1}^{\infty} \alpha_{n, i}\left\langle q, J S_{i}^{n} x_{n}\right\rangle+\left\|\alpha_{n, 0} J x_{n}+\sum_{i=1}^{\infty} \alpha_{n, i} J S_{i}^{n} x_{n}\right\|^{2} \\
\leq & \|q\|^{2}-2 \alpha_{n, 0}\left\langle q, J x_{n}\right\rangle-2 \sum_{i=1}^{\infty} \alpha_{n, i}\left\langle q, J S_{i}^{n} x_{n}\right\rangle+\alpha_{n, 0}\left\|J x_{n}\right\|^{2}+\sum_{i=1}^{\infty} \alpha_{n, i}\left\|J S_{i}^{n} x_{n}\right\|^{2} \\
& -\alpha_{n, 0} \alpha_{n, j} g\left\|J x_{n}-J S_{j}^{n} x_{n}\right\| \\
= & \|q\|^{2}-2 \alpha_{n, 0}\left\langle q, J x_{n}\right\rangle+\alpha_{n, 0}\left\|J x_{n}\right\|^{2}-2 \sum_{i=1}^{\infty} \alpha_{n, i}\left\langle q, J S_{i}^{n} x_{n}\right\rangle \\
& +\sum_{i=1}^{\infty} \alpha_{n, i}\left\|J S_{i}^{n} x_{n}\right\|^{2}-\alpha_{n, 0} \alpha_{n, j} g\left\|J x_{n}-J S_{j}^{n} x_{n}\right\| \\
\leq & \alpha_{n, 0} \phi\left(q, x_{n}\right)+\sum_{i=1}^{\infty} \alpha_{n, i} \phi\left(q, S_{i}^{n} x_{n}\right)-\alpha_{n, 0} \alpha_{n, j} g\left\|J x_{n}-J S_{j}^{n} x_{n}\right\| \\
\leq & \alpha_{n, 0} k_{n} \phi\left(q, x_{n}\right)+\sum_{i=1}^{\infty} \alpha_{n, i} k_{n} \phi\left(q, x_{n}\right) . \\
&
\end{aligned}
$$


Substituting (3.4) into (3.3), we get

$$
\begin{aligned}
\phi\left(q, u_{n}\right) & \leq \beta_{n} \phi\left(q, x_{n}\right)+\left(1-\beta_{n}\right) \phi\left(q, z_{n}\right) \\
& \leq \beta_{n} \phi\left(q, x_{n}\right)+\left(1-\beta_{n}\right) k_{n} \phi\left(q, x_{n}\right) \\
& \leq \beta_{n} \phi\left(q, x_{n}\right)+\left(1-\beta_{n}\right)\left[\phi\left(q, x_{n}\right)+\sup _{q \in F}\left(k_{n}-1\right) \phi\left(q, x_{n}\right)\right] \\
& \leq \phi\left(q, x_{n}\right)+\left(1-\beta_{n}\right) \sup _{q \in F}\left(k_{n}-1\right) \phi\left(q, x_{n}\right) \\
& \leq \phi\left(q, x_{n}\right)+\theta_{n} .
\end{aligned}
$$

This show that $q \in C_{n+1}$ implies that $F \subset C_{n+1}$ and hence, $F \subset C_{n}$ for all $n \geq 0$. Since $F$ is nonempty, $C_{n}$ is a nonempty closed convex subset of $E$, and hence $\Pi_{C_{n}}$ exist for all $n \geq 0$. This implies that the sequence $\left\{x_{n}\right\}$ is well defined. From definition of $C_{n+1}$ that $x_{n}=\Pi_{C_{n}} x_{0}$ and $x_{n+1}=\prod_{C_{n+1}} x_{0}$, we have

$$
\phi\left(x_{n}, x_{0}\right) \leq \phi\left(x_{n+1}, x_{0}\right), \quad \forall n \geq 0 .
$$

By Lemma 2.3, we also have

$$
\begin{aligned}
\phi\left(x_{n}, x_{0}\right) & =\phi\left(\Pi_{C_{n}} x_{0}, x_{0}\right) \\
& \leq \phi\left(q, x_{0}\right)-\phi\left(q, x_{n}\right) \\
& \leq \phi\left(q, x_{0}\right), \quad \forall q \in F \subset C_{n}, \forall n \geq 0 .
\end{aligned}
$$

From (3.6) and (3.7), then $\left\{\phi\left(x_{n}, x_{0}\right)\right\}$ are nondecreasing and bounded. So, we obtain that $\lim _{n \rightarrow \infty} \phi\left(x_{n}, x_{0}\right)$ exists. In particular, by (1.6), the sequence $\left\{\left(\left\|x_{n}\right\|-\left\|x_{0}\right\|\right)^{2}\right\}$ is bounded. This implies that $\left\{x_{n}\right\}$ is also bounded. Denote

$$
K=\sup _{n \geq 0}\left\{\left\|x_{n}\right\|\right\}<\infty
$$

Moreover, by the definition of $\left\{\theta_{n}\right\}$ and (3.8), it follows that

$$
\theta_{n} \longrightarrow 0, \quad n \longrightarrow \infty
$$

Next, we show that $\left\{x_{n}\right\}$ is a Cauchy sequence in $C$. Since $x_{m}=\Pi_{C_{m}} x_{0} \in C_{m} \subset C_{n}$, for $m>n$, by Lemma 2.3 , we have

$$
\begin{aligned}
\phi\left(x_{m}, x_{n}\right) & =\phi\left(x_{m}, \Pi_{C_{n}} x_{0}\right) \\
& \leq \phi\left(x_{m}, x_{0}\right)-\phi\left(\Pi_{C_{n}} x_{0}, x_{0}\right) \\
& =\phi\left(x_{m}, x_{0}\right)-\phi\left(x_{n}, x_{0}\right) .
\end{aligned}
$$


Since $\lim _{n \rightarrow \infty} \phi\left(x_{n}, x_{0}\right)$ exists and we take $m, n \rightarrow \infty$, then, we get $\phi\left(x_{m}, x_{n}\right) \rightarrow 0$. From Lemma 2.1, we have $\lim _{n \rightarrow \infty}\left\|x_{m}-x_{n}\right\|=0$. Thus $\left\{x_{n}\right\}$ is a Cauchy sequence and by the completeness of $E$, and there exists a point $p \in C$ such that $x_{n} \rightarrow p$ as $n \rightarrow \infty$.

Now, we claim that $\left\|J u_{n}-J x_{n}\right\| \rightarrow 0$, as $n \rightarrow \infty$. By definition of $\Pi_{C_{n}} x_{0}$, one has

$$
\begin{aligned}
\phi\left(x_{n+1}, x_{n}\right) & =\phi\left(x_{n+1}, \Pi_{C_{n}} x_{0}\right) \\
& \leq \phi\left(x_{n+1}, x_{0}\right)-\phi\left(\Pi_{C_{n}} x_{0}, x_{0}\right) \\
& =\phi\left(x_{n+1}, x_{0}\right)-\phi\left(x_{n}, x_{0}\right) .
\end{aligned}
$$

Since $\lim _{n \rightarrow \infty} \phi\left(x_{n}, x_{0}\right)$ exists, we have

$$
\lim _{n \rightarrow \infty} \phi\left(x_{n+1}, x_{n}\right)=0
$$

By Lemma 2.1, we obtain that

$$
\lim _{n \rightarrow \infty}\left\|x_{n+1}-x_{n}\right\|=0
$$

Since $J$ is uniformly norm-to-norm continuous on bounded subsets of $E$, we get

$$
\lim _{n \rightarrow \infty}\left\|J x_{n+1}-J x_{n}\right\|=0
$$

From $x_{n+1}=\Pi_{C_{n+1}} x_{0} \in C_{n+1} \subset C_{n}$ and the definition of $C_{n+1}$, we have

$$
\phi\left(x_{n+1}, u_{n}\right) \leq \phi\left(x_{n+1}, x_{n}\right)+\theta_{n} .
$$

By (3.9) and (3.12), we also have

$$
\lim _{n \rightarrow \infty} \phi\left(x_{n+1}, u_{n}\right)=0
$$

Applying Lemma 2.1, we obtain

$$
\lim _{n \rightarrow \infty}\left\|x_{n+1}-u_{n}\right\|=0
$$

Since $\left\|u_{n}-x_{n}\right\| \leq\left\|u_{n}-x_{n+1}\right\|+\left\|x_{n+1}-x_{n}\right\|$, we get

$$
\lim _{n \rightarrow \infty}\left\|u_{n}-x_{n}\right\|=0
$$

Since $J$ is uniformly norm-to-norm continuous on bounded subsets of $E$, we have

$$
\lim _{n \rightarrow \infty}\left\|J u_{n}-J x_{n}\right\|=0
$$


Next, we will show that $x_{n} \rightarrow p \in F:=\operatorname{GEP}(f, B) \cap\left(\cap_{i=1}^{\infty} F\left(S_{i}\right)\right)$.

(i) First, we show that $x_{n} \rightarrow p \in G E P(f, B)$. It follows from (3.3) and (3.4) we observe that $\phi\left(p, y_{n}\right) \leq \phi\left(p, x_{n}\right)+\theta_{n}$. By Lemma 2.6 and $u_{n}=T_{r_{n}} y_{n}$, we obtain

$$
\begin{aligned}
\phi\left(u_{n}, y_{n}\right) & =\phi\left(T_{r_{n}} y_{n}, y_{n}\right) \\
& \leq \phi\left(p, y_{n}\right)-\phi\left(p, T_{r_{n}} y_{n}\right) \\
& \leq \phi\left(p, x_{n}\right)-\phi\left(p, T_{r_{n}} y_{n}\right)+\theta_{n} \\
& =\phi\left(p, x_{n}\right)-\phi\left(p, u_{n}\right)+\theta_{n} \\
& =\|p\|^{2}-2\left\langle p, J x_{n}\right\rangle+\left\|x_{n}\right\|^{2}-\left(\|p\|^{2}-2\left\langle p, J u_{n}\right\rangle+\left\|u_{n}\right\|^{2}\right)+\theta_{n} \\
& =\left\|x_{n}\right\|^{2}-\left\|u_{n}\right\|^{2}-2\left\langle p, J x_{n}-J u_{n}\right\rangle+\theta_{n} \\
& \leq\left\|x_{n}-u_{n}\right\|\left(\left\|x_{n}\right\|+\left\|u_{n}\right\|\right)+2\|p\|\left\|J x_{n}-J u_{n}\right\|+\theta_{n} .
\end{aligned}
$$

By Lemma 2.1, (3.9), (3.18), and (3.19), we have

$$
\lim _{n \rightarrow \infty}\left\|u_{n}-y_{n}\right\|=0
$$

Again since $J$ is uniformly norm-to-norm continuous, we also have

$$
\lim _{n \rightarrow \infty}\left\|J u_{n}-J y_{n}\right\|=0
$$

From (A2), we note that

$$
\left\langle B y_{n}, y-u_{n}\right\rangle+\frac{1}{r_{n}}\left\langle y-u_{n}, J u_{n}-J y_{n}\right\rangle \geq-f\left(u_{n}, y\right) \geq f\left(y, u_{n}\right), \quad \forall y \in C,
$$

and hence

$$
\left\langle B y_{n}, y-u_{n}\right\rangle+\left\langle y-u_{n}, \frac{J u_{n}-J y_{n}}{r_{n}}\right\rangle \geq f\left(y, u_{n}\right), \quad \forall y \in C
$$

For $t$ with $0<t<1$ and $y \in C$, let $y_{t}=t y+(1-t) p$. Then $y_{t} \in C$ and hence

$$
0 \geq-\left\langle B y_{n}, y_{t}-u_{n}\right\rangle-\left\langle y_{t}-u_{n}, \frac{J u_{n}-J y_{n}}{r_{n}}\right\rangle+f\left(y_{t}, u_{n}\right), \quad \forall y \in C .
$$


It follows that

$$
\begin{aligned}
\left\langle B y_{t}, y_{t}-u_{n}\right\rangle \geq & \left\langle B y_{t}, y_{t}-u_{n}\right\rangle-\left\langle B y_{n}, y_{t}-u_{n}\right\rangle-\left\langle y_{t}-u_{n}, \frac{J u_{n}-J y_{n}}{r_{n}}\right\rangle+f\left(y_{t}, u_{n}\right), \quad \forall y_{t} \in C \\
= & \left\langle B y_{t}, y_{t}-u_{n}\right\rangle-\left\langle B u_{n}, y_{t}-u_{n}\right\rangle+\left\langle B u_{n}, y_{t}-u_{n}\right\rangle \\
& -\left\langle B y_{n}, y_{t}-u_{n}\right\rangle-\left\langle y_{t}-u_{n}, \frac{J u_{n}-J y_{n}}{r_{n}}\right\rangle+f\left(y_{t}, u_{n}\right), \quad \forall y_{t} \in C \\
= & \left\langle B y_{t}-B u_{n}, y_{t}-u_{n}\right\rangle+\left\langle B u_{n}-B y_{n}, y_{t}-u_{n}\right\rangle-\left\langle y_{t}-u_{n}, \frac{J u_{n}-J y_{n}}{r_{n}}\right\rangle \\
& +f\left(y_{t}, u_{n}\right), \quad \forall y_{t} \in C .
\end{aligned}
$$

Since $x_{n} \rightarrow p$ as $n \rightarrow \infty$ from (3.18) and (3.21), we can get $u_{n} \rightarrow p$ and $y_{n} \rightarrow p$ as $n \rightarrow \infty$. Furthermore, it follows from the continuity of $B$ that $B u_{n}-B y_{n} \rightarrow 0$ as $n \rightarrow \infty$. From $r_{n}>0$ and (3.22), we have $\left\|J u_{n}-J y_{n}\right\| / r_{n} \rightarrow 0$ as $n \rightarrow \infty$. Since $B$ is monotone, we know that $\left\langle B y_{t}-B u_{n}, y_{t}-u_{n}\right\rangle \geq 0$. Thus, it follows from (A4) that

$$
\begin{aligned}
f\left(y_{t}, p\right) & \leq \liminf _{n \rightarrow \infty} f\left(y_{t}, u_{n}\right) \\
& \leq \lim _{n \rightarrow \infty}\left\langle B y_{t}, y_{t}-u_{n}\right\rangle \\
& =\left\langle B y_{t}, y_{t}-p\right\rangle .
\end{aligned}
$$

From the conditions (A1) and (A4), we have

$$
\begin{aligned}
0 & =f\left(y_{t}, y_{t}\right) \\
& \leq t f\left(y_{t}, y\right)+(1-t) f\left(y_{t}, p\right) \\
& \leq t f\left(y_{t}, y\right)+(1-t)\left\langle B y_{t}, y_{t}-p\right\rangle \\
& \leq t f\left(y_{t}, y\right)+(1-t) t\left\langle B y_{t}, y-p\right\rangle,
\end{aligned}
$$

and hence

$$
0 \leq f\left(y_{t}, y\right)+(1-t)\left\langle B y_{t}, y-p\right\rangle
$$

Letting $t \rightarrow 0$, we get

$$
0 \leq f(p, y)+\langle B p, y-p\rangle, \quad \forall y \in C
$$

This implies that $p \in G E P(f, B)$. 
(ii) We show that $x_{n} \rightarrow p \in \cap_{i=1}^{\infty} F\left(S_{i}\right)$. From definition of $C_{n+1}$ and since $x_{n+1}=$ $\Pi_{C_{n+1}} x_{0} \in C_{n+1}$, we have

$$
\phi\left(x_{n+1}, z_{n}\right) \leq \phi\left(x_{n+1}, x_{n}\right)+\theta_{n} .
$$

Form Lemma 2.1 and (3.9), we obtain that

$$
\lim _{n \rightarrow \infty}\left\|x_{n+1}-z_{n}\right\|=0
$$

Since $J$ is uniformly norm-to-norm continuous, we also have

$$
\lim _{n \rightarrow \infty}\left\|J x_{n+1}-J z_{n}\right\|=0 .
$$

From (3.1), we compute

$$
\begin{aligned}
\left\|J x_{n+1}-J z_{n}\right\| & =\left\|J x_{n+1}-\left(\alpha_{n, 0} J x_{n}+\sum_{i=1}^{\infty} \alpha_{n, i} J S_{i}^{n} x_{n}\right)\right\| \\
& =\left\|\alpha_{n, 0} J x_{n+1}-\alpha_{n, 0} J x_{n}+\sum_{i=1}^{\infty} \alpha_{n, i} J x_{n+1}-\sum_{i=1}^{\infty} \alpha_{n, i} J S_{i}^{n} x_{n}\right\| \\
& =\left\|\alpha_{n, 0}\left(J x_{n+1}-J x_{n}\right)+\sum_{i=1}^{\infty} \alpha_{n, i}\left(J x_{n+1}-J S_{i}^{n} x_{n}\right)\right\| \\
& =\left\|\sum_{i=1}^{\infty} \alpha_{n, i}\left(J x_{n+1}-J S_{i}^{n} x_{n}\right)-\alpha_{n, 0}\left(J x_{n}-J x_{n+1}\right)\right\| \\
& \geq \sum_{i=1}^{\infty} \alpha_{n, i}\left\|J x_{n+1}-J S_{i}^{n} x_{n}\right\|-\alpha_{n, 0}\left\|J x_{n}-J x_{n+1}\right\|,
\end{aligned}
$$

and hence

$$
\left\|J x_{n+1}-J S_{i}^{n} x_{n}\right\| \leq \frac{1}{\sum_{i=1}^{\infty} \alpha_{n, i}}\left(\left\|J x_{n+1}-J z_{n}\right\|+\alpha_{n, 0}\left\|J x_{n}-J x_{n+1}\right\|\right) .
$$

From (3.14), (3.33), and $\lim \inf _{n \rightarrow \infty} \sum_{i=1}^{\infty} \alpha_{n, i}>0$, we get

$$
\lim _{n \rightarrow \infty}\left\|J x_{n+1}-J S_{i}^{n} x_{n}\right\|=0
$$

Since $J^{-1}$ is uniformly norm-to-norm continuous on bounded sets, we obtain that

$$
\lim _{n \rightarrow \infty}\left\|x_{n+1}-S_{i}^{n} x_{n}\right\|=0
$$


By the triangle inequality,

$$
\begin{aligned}
\left\|x_{n}-S_{i}^{n} x_{n}\right\| & =\left\|x_{n}-x_{n+1}+x_{n+1}-S_{i}^{n} x_{n}\right\| \\
& \leq\left\|x_{n}-x_{n+1}\right\|+\left\|x_{n+1}-S_{i}^{n} x_{n}\right\| .
\end{aligned}
$$

Hence from (3.13) and (3.37), we have

$$
\lim _{n \rightarrow \infty}\left\|x_{n}-S_{i}^{n} x_{n}\right\|=0
$$

Since $J$ is uniformly continuous on any bounded subset of $E$, we obtain

$$
\lim _{n \rightarrow \infty}\left\|J x_{n}-J S_{i}^{n} x_{n}\right\|=0, \quad \forall i \geq 1
$$

Since $x_{n} \rightarrow p$ and $J$ is uniformly continuous, it yields $J x_{n} \rightarrow J p$. Thus from (3.40), we get

$$
J S_{i}^{n} x_{n} \longrightarrow J p, \quad \forall i \geq 1
$$

Since $J^{-1}: E^{*} \rightarrow E$ is norm-weak ${ }^{*}$-continuous, we have

$$
S_{i}^{n} x_{n}-p, \quad \forall i \geq 1
$$

On the other hand, for each $i \geq 1$, we observe that

$$
\left|\left\|S_{i}^{n} x_{n}\right\|-\|p\|\right|=\left|\left\|J\left(S_{i}^{n} x_{n}\right)\right\|-\|J p\|\right| \leq\left\|J\left(S_{i}^{n} x_{n}\right)-J p\right\| .
$$

In view of (3.41), we obtain $\left\|S_{i}^{n} x_{n}\right\| \rightarrow\|p\|$ for each $i \geq 1$. Since $E$ has the Kadec-Klee property, we get

$$
S_{i}^{n} x_{n} \longrightarrow p, \quad \text { for each } i \geq 1 \text {. }
$$

By the assumption that for each $i \geq 1, S_{i}$ is uniformly $L_{i}$-Lipschitz continuous, we have

$$
\begin{aligned}
\left\|S_{i}^{n+1} x_{n}-S_{i}^{n} x_{n}\right\| & \leq\left\|S_{i}^{n+1} x_{n}-S_{i}^{n+1} x_{n+1}\right\|+\left\|S_{i}^{n+1} x_{n+1}-x_{n+1}\right\|+\left\|x_{n+1}-x_{n}\right\|+\left\|x_{n}-S_{i}^{n} x_{n}\right\| \\
& \leq\left(L_{i}+1\right)\left\|x_{n+1}-x_{n}\right\|+\left\|S_{i}^{n+1} x_{n+1}-x_{n+1}\right\|+\left\|x_{n}-S_{i}^{n} x_{n}\right\| .
\end{aligned}
$$

From (3.13) and (3.39), it yields that $\left\|S_{i}^{n+1} x_{n}-S_{i}^{n} x_{n}\right\| \rightarrow 0$. From $S_{i}^{n} x_{n} \rightarrow p$, we get $S_{i}^{n+1} x_{n} \rightarrow$ $p$, that is $S_{i} S_{i}^{n} x_{n} \rightarrow p$. In view of closeness of $S_{i}$, we have $S_{i} p=p$, for all $i \geq 1$. This implies that $p \in \cap_{i=1}^{\infty} F\left(S_{i}\right)$. 

we have

Finally, we show that $x_{n} \rightarrow p=\Pi_{F} x_{0}$. Let $u=\Pi_{F} x_{0}$. From $x_{n}=\Pi_{C_{n}} x_{0}$ and $u \in F \subset C_{n}$,

$$
\phi\left(x_{n}, x_{0}\right) \leq \phi\left(u, x_{0}\right), \quad \forall n \geq 0 .
$$

This implies that

$$
\phi\left(p, x_{0}\right)=\lim _{n \rightarrow \infty} \phi\left(x_{n}, x_{0}\right) \leq \phi\left(u, x_{0}\right) .
$$

By definition of $p=\Pi_{F} x_{0}$, we have $p=u$. Therefore, $x_{n} \rightarrow p=\Pi_{F} x_{0}$. This completes the proof.

If $S_{i}=S$ for each $i \in \mathbb{N}$, then Theorem 3.1 is reduced to the following corollary.

Corollary 3.2. Let $C$ be a nonempty closed and convex subset of a uniformly smooth and strictly convex Banach space $E$ with Kadec-Klee property. Let $f$ be a bifunction from $C \times C$ to $\mathbb{R}$ satisfying $(A 1)-(A 4)$. Let $B$ be a continuous monotone mapping of $C$ into $E^{*}$. Let $S: C \rightarrow C$ be a closed uniformly L-Lipschitz continuous and quasi- $\phi$-asymptotically nonexpansive mappings with a sequence $\left\{k_{n}\right\} \subset[1, \infty), k_{n} \rightarrow 1$, such that $F:=F(S) \cap G E P(f, B)$ is a nonempty and bounded subset in C. For an initial point $x_{0} \in E$ with $x_{1}=\Pi_{C_{1}} x_{0}$ and $C_{1}=C$, we define the sequence $\left\{x_{n}\right\}$ as follows:

$$
\begin{gathered}
y_{n}=J^{-1}\left(\beta_{n} J x_{n}+\left(1-\beta_{n}\right) J z_{n}\right), \\
z_{n}=J^{-1}\left(\alpha_{n} J x_{n}+\left(1-\alpha_{n}\right) J S^{n} x_{n}\right), \\
u_{n} \in C \text { such that } f\left(u_{n}, y\right)+\left\langle B y_{n}, y-u_{n}\right\rangle+\frac{1}{r_{n}}\left\langle y-u_{n}, J u_{n}-J y_{n}\right\rangle \geq 0, \quad \forall y \in C, \\
C_{n+1}=\left\{z \in C_{n}: \phi\left(z, u_{n}\right) \leq \phi\left(z, x_{n}\right)+\theta_{n}\right\}, \\
x_{n+1}=\prod_{C_{n+1}} x_{0}, \quad \forall n \geq 0,
\end{gathered}
$$

where $J$ is the duality mapping on $E, \theta_{n}=\sup _{q \in F}\left(k_{n}-1\right) \phi\left(q, x_{n}\right),\left\{\alpha_{n}\right\},\left\{\beta_{n}\right\}$ are sequences in $[0,1]$, and $\left\{r_{n}\right\} \subset[a, \infty)$ for some $a>0$. If $\lim \inf _{n \rightarrow \infty} \alpha_{n}\left(1-\alpha_{n}\right)>0$, then $\left\{x_{n}\right\}$ converges strongly to $p \in F$, where $p=\Pi_{F} x_{0}$.

For a special case that $i=1,2$, we can obtain the following results on a pair of quasi- $\phi$ asymptotically nonexpansive mappings immediately from Theorem 3.1.

Corollary 3.3. Let $C$ be a nonempty closed and convex subset of a uniformly smooth and strictly convex Banach space $E$ with Kadec-Klee property. Let $f$ be a bifunction from $C \times C$ to $\mathbb{R}$ satisfying $(A 1)-(A 4)$. Let $B$ be a continuous monotone mapping of $C$ into $E^{*}$. Let $S, T: C \rightarrow C$ be two closed quasi- $\phi$-asymptotically nonexpansive mappings and uniformly $L_{S}, L_{T}$-Lipschitz continuous, respectively with a sequence $\left\{k_{n}\right\} \subset[1, \infty), k_{n} \rightarrow 1$ such that $F:=F(S) \cap F(T) \cap G E P(f, B)$ is a 
nonempty and bounded subset in $C$. For an initial point $x_{0} \in E$ with $x_{1}=\Pi_{C_{1}} x_{0}$ and $C_{1}=C$, we define the sequence $\left\{x_{n}\right\}$ as follows:

$$
\begin{gathered}
y_{n}=J^{-1}\left(\beta_{n} J x_{n}+\left(1-\beta_{n}\right) J z_{n}\right), \\
z_{n}=J^{-1}\left(\alpha_{n} J x_{n}+\beta_{n} J S^{n} x_{n}+\gamma_{n} J T^{n} x_{n}\right), \\
u_{n} \in C \text { such that } f\left(u_{n}, y\right)+\left\langle B y_{n}, y-u_{n}\right\rangle+\frac{1}{r_{n}}\left\langle y-u_{n} J u_{n}-J y_{n}\right\rangle \geq 0, \quad \forall y \in C, \\
C_{n+1}=\left\{z \in C_{n}: \phi\left(z, u_{n}\right) \leq \phi\left(z, x_{n}\right)+\theta_{n}\right\}, \\
x_{n+1}=\prod_{C_{n+1}} x_{0}, \quad \forall n \geq 0,
\end{gathered}
$$

where $J$ is the duality mapping on $E, \theta_{n}=\sup _{q \in F}\left(k_{n}-1\right) \phi\left(q, x_{n}\right),\left\{\alpha_{n, i}\right\},\left\{\beta_{n}\right\}$ are sequences in $[0,1]$, and $\left\{r_{n}\right\} \subset[a, \infty)$ for some $a>0$. If $\alpha_{n}+\beta_{n}+\gamma_{n}=1$ for all $n \geq 0$ and $\lim _{\inf _{n \rightarrow \infty}} \alpha_{n} \beta_{n}>0$ and $\lim \inf _{n \rightarrow \infty} \alpha_{n} \gamma_{n}>0$, then $\left\{x_{n}\right\}$ converges strongly to $p \in F$, where $p=\Pi_{F} x_{0}$.

Remark 3.4. Corollary 3.3 improves and extends [44, Theorem 3.1] in the following senses:

(i) for the mappings, we extend the mappings from two closed relatively quasinonexpansive mappings to an infinite family of closed and uniformly quasi- $\phi$ asymptotically mappings,

(ii) from a solution of the classical equilibrium problem to the generalized equilibrium problem,

(iii) for the framework of spaces, we extend the space from a uniformly smooth and uniformly convex Banach space to a uniformly smooth and strictly convex Banach space with the Kadec-Klee property.

Corollary 3.5. Let $C$ be a nonempty closed and convex subset of a uniformly smooth and strictly convex Banach space $E$ with Kadec-Klee property. Let $f$ be a bifunction from $C \times C$ to $\mathbb{R}$ satisfying $(A 1)-(A 4)$. Let $B$ be a continuous monotone mapping of $C$ into $E^{*}$. Let $\left\{S_{i}\right\}_{i=1}^{\infty}: C \rightarrow C$ be an infinite family of closed quasi- $\phi$-nonexpansive mappings such that $F:=\cap_{i=1}^{\infty} F\left(S_{i}\right) \cap G E P(f, B) \neq \emptyset$. For an initial point $x_{0} \in E$ with $x_{1}=\Pi_{C_{1}} x_{0}$ and $C_{1}=C$, we define the sequence $\left\{x_{n}\right\}$ as follows:

$$
\begin{gathered}
y_{n}=J^{-1}\left(\beta_{n} J x_{n}+\left(1-\beta_{n}\right) J z_{n}\right), \\
z_{n}=J^{-1}\left(\alpha_{n, 0} J x_{n}+\sum_{i=1}^{\infty} \alpha_{n, i} J S_{i} x_{n}\right), \\
u_{n} \in C \text { such that } f\left(u_{n}, y\right)+\left\langle B y_{n}, y-u_{n}\right\rangle+\frac{1}{r_{n}}\left\langle y-u_{n}, J u_{n}-J y_{n}\right\rangle \geq, \quad \forall y \in C, \\
C_{n+1}=\left\{z \in C_{n}: \phi\left(z, u_{n}\right) \leq \phi\left(z, x_{n}\right)\right\}, \\
x_{n+1}=\prod_{C_{n+1}} x_{0}, \quad \forall n \geq 0,
\end{gathered}
$$

where $J$ is the duality mapping on $E,\left\{\alpha_{n, i}\right\},\left\{\beta_{n}\right\}$ are sequences in $[0,1]$, and $\left\{r_{n}\right\} \subset[a, \infty)$ for some $a>0$. If $\sum_{i=0}^{\infty} \alpha_{n, i}=1$ for all $n \geq 0$ and $\lim _{\inf _{n \rightarrow \infty}} \alpha_{n, 0} \alpha_{n, i}>0$ for all $i \geq 1$, then $\left\{x_{n}\right\}$ converges strongly to $p \in F$, where $p=\Pi_{F} x_{0}$. 
Proof. Since $\left\{S_{i}\right\}_{i=1}^{\infty}: C \rightarrow C$ is an infinite family of closed quasi- $\phi$-nonexpansive mappings, it is an infinite family of closed and uniformly quasi- $\phi$-asymptotically nonexpansive mappings with sequence $k_{n}=1$. Hence the conditions appearing in Theorem 3.1 F is a bounded subset in $C$ and for each $i \geq 1, S_{i}$ is uniformly $L_{i}$-Lipschitz continuous are of no use here. By virtue of the closeness of mapping $S_{i}$ for each $i \geq 1$, it yields that $p \in F\left(S_{i}\right)$ for each $i \geq 1$, that is, $p \in \cap_{i=1}^{\infty} F\left(S_{i}\right)$. Therefore, all conditions in Theorem 3.1 are satisfied. The conclusion of Corollary 3.5 is obtained from Theorem 3.1 immediately.

Corollary 3.6. Let $C$ be a nonempty closed and convex subset of a uniformly smooth and strictly convex Banach space $E$ with Kadec-Klee property. Let $f$ be a bifunction from $C \times C$ to $\mathbb{R}$ satisfying $(A 1)-(A 4)$. Let $B$ be a continuous monotone mapping of $C$ into $E^{*}$. Let $\left\{S_{i}\right\}_{i=1}^{\infty}: C \rightarrow C$ be an infinite family of closed and uniformly quasi- $\phi$-asymptotically nonexpansive mappings with a sequence $\left\{k_{n}\right\} \subset$ $[1, \infty), k_{n} \rightarrow 1$ and uniformly $L_{i}$-Lipschitz continuous such that $F:=\cap_{i=1}^{\infty} F\left(S_{i}\right) \cap G E P(f, B)$ is a nonempty and bounded subset in $C$. For an initial point $x_{0} \in E$ with $x_{1}=\Pi_{C_{1}} x_{0}$ and $C_{1}=C$, we define the sequence $\left\{x_{n}\right\}$ as follows:

$$
\begin{gathered}
y_{n}=J^{-1}\left(\alpha_{n, 0} J x_{n}+\sum_{i=1}^{\infty} \alpha_{n, i} J S_{i}^{n} x_{n}\right), \\
u_{n} \in C \text { such that } f\left(u_{n}, y\right)+\left\langle B y_{n}, y-u_{n}\right\rangle+\frac{1}{r_{n}}\left\langle y-u_{n}, J u_{n}-J y_{n}\right\rangle \geq 0, \quad \forall y \in C, \\
C_{n+1}=\left\{z \in C_{n}: \phi\left(z, u_{n}\right) \leq \phi\left(z, x_{n}\right)+\theta_{n}\right\}, \\
x_{n+1}=\prod_{C_{n+1}} x_{0}, \quad \forall n \geq 0,
\end{gathered}
$$

where $J$ is the duality mapping on $E, \theta_{n}=\sup _{q \in F}\left(k_{n}-1\right) \phi\left(q, x_{n}\right),\left\{\alpha_{n, i}\right\}$ is a sequence in $[0,1]$, and $\left\{r_{n}\right\} \subset[a, \infty)$ for some $a>0$. If $\sum_{i=0}^{\infty} \alpha_{n, i}=1$ for all $n \geq 0$ and $\lim _{\inf } \ln _{n \rightarrow \infty} \alpha_{n, 0} \alpha_{n, i}>0$ for all $i \geq 1$, then $\left\{x_{n}\right\}$ converges strongly to $p \in F$, where $p=\Pi_{F} x_{0}$.

Proof. Setting $\beta_{n} \equiv 0$ in Theorem 3.1, then, we get that $y_{n}=z_{n}$. Thus, the method of proof of Theorem 3.1 we obtain Corollary 3.6 immediately.

Remark 3.7. Theorem 3.1, Corollary 3.3, and Corollary 3.5, improve and extend the corresponding results in Qin et al. [49] and Zegeye [50] in the following senses:

(i) from a solution of the classical equilibrium problem to the generalized equilibrium problem with an infinite family of quasi- $\phi$-asymptotically mappings,

(ii) for the mappings, we extend the mappings from nonexpansive mappings, relatively quasi-nonexpansive mappings or quasi- $\phi$-nonexpansive mappings and a finite family of closed relatively quasi-nonexpansive mappings to an infinite family of quasi- $\phi$-asymptotically nonexpansive mappings,

(iii) for the framework of spaces, we extend the space from a uniformly smooth and uniformly convex Banach space to a uniformly smooth and strictly convex Banach space with the Kadec-Klee property. 


\section{Applications}

If $E=H$, a Hilbert space, then $H$ is uniformly smooth and strictly convex Banach space $E$ with Kadec-Klee property and closed relatively quasi-nonexpansive mappings reducing to closed quasi-nonexpansive mappings. Moreover, $J=I$, identity operator on $H$ and $\Pi_{C}=P_{C}$, projection mapping from $H$ into $C$. Thus, the following corollaries hold.

Theorem 4.1. Let $C$ be a nonempty closed and convex subset of a Hilbert space $H$. Let $f$ be a bifunction from $C \times C$ to $\mathbb{R}$ satisfying $(A 1)-(A 4)$. Let $B$ be a continuous monotone mapping of $C$ into $H$. Let $\left\{S_{i}\right\}_{i=1}^{\infty}: C \rightarrow C$ be an infinite family of closed and uniformly quasi- $\phi$-asymptotically nonexpansive mappings with a sequence $\left\{k_{n}\right\} \subset[1, \infty), k_{n} \rightarrow 1$ and uniformly $L_{i}$-Lipschitz continuous such that $F:=\cap_{i=1}^{\infty} F\left(S_{i}\right) \cap G E P(f, B)$ is a nonempty and bounded subset in $C$. For an initial point $x_{0} \in H$ with $x_{1}=P_{C_{1}} x_{0}$ and $C_{1}=C$, we define the sequence $\left\{x_{n}\right\}$ as follows:

$$
\begin{gathered}
y_{n}=\beta_{n} x_{n}+\left(1-\beta_{n}\right) z_{n}, \\
z_{n}=\alpha_{n, 0} x_{n}+\sum_{i=1}^{\infty} \alpha_{n, i} S_{i}^{n} x_{n}, \\
u_{n} \in C \text { such that } f\left(u_{n}, y\right)+\left\langle B y_{n}, y-u_{n}\right\rangle+\frac{1}{r_{n}}\left\langle y-u_{n}, u_{n}-y_{n}\right\rangle \geq 0, \quad \forall y \in C, \\
C_{n+1}=\left\{z \in C_{n}:\left\|z-u_{n}\right\| \leq \alpha_{n}\left\|z-x_{n}\right\|+\left(1-\alpha_{n}\right)\left\|z-z_{n}\right\| \leq\left\|z-x_{n}\right\|+\theta_{n}\right\}, \\
x_{n+1}=P_{C_{n+1}} x_{0}, \quad \forall n \geq 0,
\end{gathered}
$$

where $\theta_{n}=\sup _{q \in F}\left(k_{n}-1\right)\left\|q-x_{n}\right\|,\left\{\alpha_{n, i}\right\},\left\{\beta_{n}\right\}$ are sequences in $[0,1]$, and $\left\{r_{n}\right\} \subset[a, \infty)$ for some $a>0$. If $\sum_{i=0}^{\infty} \alpha_{n, i}=1$ for all $n \geq 0$ and $\lim _{\inf _{n \rightarrow \infty}} \alpha_{n, 0} \alpha_{n, i}>0$ for all $i \geq 1$, then $\left\{x_{n}\right\}$ converges strongly to $p \in F$, where $p=\Pi_{F} x_{0}$.

Corollary 4.2. Let $C$ be a nonempty closed and convex subset of a Hilbert space $H$. Let $f$ be a bifunction from $C \times C$ to $\mathbb{R}$ satisfying $(A 1)-(A 4)$. Let $B$ be a continuous monotone mapping of $C$ into $H$. Let $\left\{S_{i}\right\}_{i=1}^{\infty}: C \rightarrow C$ be an infinite family of closed and quasi- $\phi$-nonexpansive mappings with a sequence $\left\{k_{n}\right\} \subset[1, \infty), k_{n} \rightarrow 1$ and uniformly $L_{i}$-Lipschitz continuous such that $F:=\cap_{i=1}^{\infty} F\left(S_{i}\right) \cap G E P(f, B)$ is a nonempty and bounded subset in $C$. For an initial point $x_{0} \in H$ with $x_{1}=P_{C_{1}} x_{0}$ and $C_{1}=C$, we define the sequence $\left\{x_{n}\right\}$ as follows:

$$
\begin{gathered}
y_{n}=\beta_{n} x_{n}+\left(1-\beta_{n}\right) z_{n}, \\
z_{n}=\alpha_{n, 0} x_{n}+\sum_{i=1}^{\infty} \alpha_{n, i} S_{i}^{n} x_{n}, \\
u_{n} \in C \text { such that } f\left(u_{n}, y\right)+\left\langle B y_{n}, y-u_{n}\right\rangle+\frac{1}{r_{n}}\left\langle y-u_{n}, u_{n}-y_{n}\right\rangle \geq 0, \quad \forall y \in C, \\
C_{n+1}=\left\{z \in C_{n}:\left\|z-u_{n}\right\| \leq \alpha_{n}\left\|z-x_{n}\right\|+\left(1-\alpha_{n}\right)\left\|z-z_{n}\right\| \leq\left\|z-x_{n}\right\|\right\}, \\
x_{n+1}=P_{C_{n+1}} x_{0}, \quad \forall n \geq 0,
\end{gathered}
$$

where $\left\{\alpha_{n, i}\right\},\left\{\beta_{n}\right\}$ are sequences in $[0,1]$ and $\left\{r_{n}\right\} \subset[a, \infty)$ for some $a>0$. If $\sum_{i=0}^{\infty} \alpha_{n, i}=1$ for all $n \geq$ 0 and $\lim \inf _{n \rightarrow \infty} \alpha_{n, 0} \alpha_{n, i}>0$ for all $i \geq 1$, then $\left\{x_{n}\right\}$ converges strongly to $p \in F$, where $p=\Pi_{F} x_{0}$. 
Remark 4.3. Theorem 4.1 improves and extends the Corollary 3.7 in Zegeye [50] in the aspect for the mappings; we extend the mappings from a finite family of closed relatively quasinonexpansive mappings to more general a infinite family of closed and uniformly quasi- $\phi$ asymptotically nonexpansive mappings.

\section{Acknowledgments}

The authors would like to thank the referees for their careful readings and valuable suggestions to improve the writing of this paper. The first author is supported by grant fund under the program Strategic Scholarships for Frontier Research Network for the Ph.D. Program Thai Doctoral degree from the Office of the Commission on Higher Education and the second author is supported by the Thailand Research Fund and the Commission on Higher Education under the project no. MRG5380044.

\section{References}

[1] A. Auslender, Optimization-Méthodes Numériques, Masson, Paris, France, 1976.

[2] Y. Censor, "Parallel application of block-iterative methods in medical imaging and radiation therapy," Mathematical Programming, vol. 42, no. 2, pp. 307-325, 1988.

[3] D. Butnariu and Y. Censor, "On a class of barganing schemes for points in the cores of $n$-person cooperative games," In press.

[4] P. L. Combettes, "The convex feasibility problem in inage recovery," in Advances in Imaging and Electron Physics, P. Hawkes, Ed., vol. 95, pp. 155-270, Academic Press, New York, NY, USA, 1996.

[5] S. Kitahara and W. Takahashi, "Image recovery by convex combinations of sunny nonexpansive retractions," Topological Methods in Nonlinear Analysis, vol. 2, no. 2, pp. 333-342, 1993.

[6] Y. I. Alber, "Metric and generalized projection operators in Banach spaces: properties and applications," in Theory and Applications of Nonlinear Operators of Accretive and Monotone Type, A. G. Kartsatos, Ed., vol. 178 of Lecture Notes in Pure and Applied Mathematics, pp. 15-50, Marcel Dekker, New York, NY, USA, 1996.

[7] S. Kamimura and W. Takahashi, "Strong convergence of a proximal-type algorithm in a Banach space," SIAM Journal on Optimization, vol. 13, no. 3, pp. 938-945, 2002.

[8] F. Kohsaka and W. Takahashi, "Block iterative methods for a finite family of relatively nonexpansive mappings in Banach spaces," Fixed Point Theory and Applications, vol. 2007, Article ID 21972, 18 pages, 2007.

[9] M. Kikkawa and W. Takahashi, "Approximating fixed points of nonexpansive mappings by the block iterative method in Banach spaces," International Journal of Computational and Numerical Analysis and Applications, vol. 5, no. 1, pp. 59-66, 2004.

[10] S. Plubtieng and K. Ungchittrakool, "Hybrid iterative methods for convex feasibility problems and fixed point problems of relatively nonexpansive mappings in Banach spaces," Fixed Point Theory and Applications, vol. 2008, Article ID 583082, 19 pages, 2008.

[11] E. Blum and W. Oettli, "From optimization and variational inequalities to equilibrium problems," The Mathematics Student, vol. 63, no. 1-4, pp. 123-145, 1994.

[12] G. Cai and C. S. Hu, "A hybrid approximation method for equilibrium and fixed point problems for a family of infinitely nonexpansive mappings and a monotone mapping," Nonlinear Analysis: Hybrid Systems, vol. 3, no. 4, pp. 395-407, 2009.

[13] P. L. Combettes and S. A. Hirstoaga, "Equilibrium programming in Hilbert spaces," Journal of Nonlinear and Convex Analysis, vol. 6, no. 1, pp. 117-136, 2005.

[14] Q.-L. Dong and B.-C. Deng, "Strong convergence theorem by hybrid method for equilibrium problems, variational inequality problems and maximal monotone operators," Nonlinear Analysis: Hybrid Systems. In press.

[15] C. Jaiboon and P. Kumam, "A general iterative method for solving equilibrium problems, variational inequality problems and fixed point problems of an infinite family of nonexpansive mappings," Journal of Applied Mathematics and Computing. In press. 
[16] C. Jaiboon, W. Chantarangsi, and P. Kumam, "A convergence theorem based on a hybrid relaxed extragradient method for generalized equilibrium problems and fixed point problems of a finite family of nonexpansive mappings," Nonlinear Analysis: Hybrid Systems, vol. 4, no. 1, pp. 199-215, 2010.

[17] A. Kangtunyakarn and S. Suantai, "Hybrid iterative scheme for generalized equilibrium problems and fixed point problems of finite family of nonexpansive mappings," Nonlinear Analysis: Hybrid Systems, vol. 3, no. 3, pp. 296-309, 2009.

[18] P. Katchang and P. Kumam, "A new iterative algorithm of solution for equilibrium problems, variational inequalities and fixed point problems in a Hilbert space," Journal of Applied Mathematics and Computing, vol. 32, no. 1, pp. 19-38, 2010.

[19] P. Kumam, "A hybrid approximation method for equilibrium and fixed point problems for a monotone mapping and a nonexpansive mapping," Nonlinear Analysis: Hybrid Systems, vol. 2, no. 4, pp. 1245-1255, 2008.

[20] P. Kumam, "A new hybrid iterative method for solution of equilibrium problems and fixed point problems for an inverse strongly monotone operator and a nonexpansive mapping," Journal of Applied Mathematics and Computing, vol. 29, no. 1-2, pp. 263-280, 2009.

[21] W. Kumam and P. Kumam, "Hybrid iterative scheme by a relaxed extragradient method for solutions of equilibrium problems and a general system of variational inequalities with application to optimization," Nonlinear Analysis: Hybrid Systems, vol. 3, no. 4, pp. 640-656, 2009.

[22] P. Kumam and K. Wattanawitoon, "Convergence theorems of a hybrid algorithm for equilibrium problems," Nonlinear Analysis: Hybrid Systems, vol. 3, no. 4, pp. 386-394, 2009.

[23] P. Kumam and C. Jaiboon, "A new hybrid iterative method for mixed equilibrium problems and variational inequality problem for relaxed cocoercive mappings with application to optimization problems," Nonlinear Analysis: Hybrid Systems, vol. 3, no. 4, pp. 510-530, 2009.

[24] P. Kumam and P. Katchang, "A viscosity of extragradient approximation method for finding equilibrium problems, variational inequalities and fixed point problems for nonexpansive mappings," Nonlinear Analysis: Hybrid Systems, vol. 3, no. 4, pp. 475-486, 2009.

[25] A. Moudafi, "Second-order differential proximal methods for equilibrium problems," JIPAM: Journal of Inequalities in Pure and Applied Mathematics, vol. 4, no. 1, article 18, 2003.

[26] X. Qin, Y. J. Cho, and S. M. Kang, "Convergence theorems of common elements for equilibrium problems and fixed point problems in Banach spaces," Journal of Computational and Applied Mathematics, vol. 225, no. 1, pp. 20-30, 2009.

[27] X. Qin, S. Y. Cho, and S. M. Kang, "Strong convergence of shrinking projection methods for quasi- $\phi$ nonexpansive mappings and equilibrium problems," Journal of Computational and Applied Mathematics, vol. 234, no. 3, pp. 750-760, 2010.

[28] R. Wangkeeree and U. Kamraksa, "An iterative approximation method for solving a general system of variational inequality problems and mixed equilibrium problems," Nonlinear Analysis: Hybrid Systems, vol. 3, no. 4, pp. 615-630, 2009.

[29] R. Wangkeeree and R. Wangkeeree, "Strong convergence of the iterative scheme based on the extragradient method for mixed equilibrium problems and fixed point problems of an infinite family of nonexpansive mappings," Nonlinear Analysis: Hybrid Systems, vol. 3, no. 4, pp. 719-733, 2009.

[30] Y. I. Alber and S. Reich, "An iterative method for solving a class of nonlinear operator equations in Banach spaces," Panamerican Mathematical Journal, vol. 4, no. 2, pp. 39-54, 1994.

[31] I. Cioranescu, Geometry of Banach Spaces, Duality Mappings and Nonlinear Problems, vol. 62 of Mathematics and Its Applications, Kluwer Academic Publishers, Dordrecht, The Netherlands, 1990.

[32] W. Takahashi, Nonlinear Functional Analysis, Yokohama Publishers, Yokohama, Japan, 2000, Fixed Point Theory and Its Application.

[33] S. Reich, "A weak convergence theorem for the alternating method with Bregman distances," in Theory and Applications of Nonlinear Operators of Accretive and Monotone Type, A. G. Kartsatos, Ed., vol. 178 of Lecture Notes in Pure and Applied Mathematics, pp. 313-318, Marcel Dekker, New York, NY, USA, 1996.

[34] W. Nilsrakoo and S. Saejung, "Strong convergence to common fixed points of countable relatively quasi-nonexpansive mappings," Fixed Point Theory and Applications, vol. 2008, Article ID 312454, 19 pages, 2008.

[35] Y. Su, D. Wang, and M. Shang, "Strong convergence of monotone hybrid algorithm for hemi-relatively nonexpansive mappings," Fixed Point Theory and Applications, vol. 2008, Article ID 284613, 8 pages, 2008. 
[36] H. Zegeye and N. Shahzad, "Strong convergence theorems for monotone mappings and relatively weak nonexpansive mappings," Nonlinear Analysis: Theory, Methods E Applications, vol. 70, no. 7, pp. 2707-2716, 2009.

[37] D. Butnariu, S. Reich, and A. J. Zaslavski, "Asymptotic behavior of relatively nonexpansive operators in Banach spaces," Journal of Applied Analysis, vol. 7, no. 2, pp. 151-174, 2001.

[38] D. Butnariu, S. Reich, and A. J. Zaslavski, "Weak convergence of orbits of nonlinear operators in reflexive Banach spaces," Numerical Functional Analysis and Optimization, vol. 24, no. 5-6, pp. 489-508, 2003.

[39] Y. Censor and S. Reich, "Iterations of paracontractions and firmly nonexpansive operators with applications to feasibility and optimization," Optimization, vol. 37, no. 4, pp. 323-339, 1996.

[40] S. Matsushita and W. Takahashi, "A strong convergence theorem for relatively nonexpansive mappings in a Banach space," Journal of Approximation Theory, vol. 134, no. 2, pp. 257-266, 2005.

[41] S. Saewan, P. Kumam, and K. Wattanawitoon, "Convergence theorem based on a new hybrid projection method for finding a common solution of generalized equilibrium and variational inequality problems in Banach spaces," Abstract and Applied Analysis, vol. 2010, Article ID 734126, 25 pages, 2010.

[42] K. Ball, E. A. Carlen, and E. H. Lieb, "Sharp uniform convexity and smoothness inequalities for trace norms," Inventiones Mathematicae, vol. 115, no. 3, pp. 463-482, 1994.

[43] S. Plubtieng and K. Ungchittrakool, "Strong convergence theorems for a common fixed point of two relatively nonexpansive mappings in a Banach space," Journal of Approximation Theory, vol. 149, no. 2, pp. 103-115, 2007.

[44] K. Wattanawitoon and P. Kumam, "Strong convergence theorems by a new hybrid projection algorithm for fixed point problems and equilibrium problems of two relatively quasi-nonexpansive mappings," Nonlinear Analysis: Hybrid Systems, vol. 3, no. 1, pp. 11-20, 2009.

[45] N. Petrot, K. Wattanawitoon, and P. Kumam, "A hybrid projection method for generalized mixed equilibrium problems and fixed point problems in Banach spaces," Nonlinear Analysis: Hybrid Systems. In press.

[46] W. Takahashi and K. Zembayashi, "Strong and weak convergence theorems for equilibrium problems and relatively nonexpansive mappings in Banach spaces," Nonlinear Analysis: Theory, Methods $\mathcal{E}$ Applications, vol. 70, no. 1, pp. 45-57, 2009.

[47] W. Takahashi and K. Zembayashi, "Strong convergence theorem by a new hybrid method for equilibrium problems and relatively nonexpansive mappings," Fixed Point Theory and Applications, vol. 2008, Article ID 528476, 11 pages, 2008.

[48] S.-S. Chang, J. K. Kim, and X. R. Wang, "Modified block iterative algorithm for solving convex feasibility problems in Banach spaces," Journal of Inequalities and Applications, vol. 2010, Article ID 869684, 14 pages, 2010.

[49] X. Qin, S. Y. Cho, and S. M. Kang, "On hybrid projection methods for asymptotically quasi- $\phi$ nonexpansive mappings," Applied Mathematics and Computation, vol. 215, no. 11, pp. 3874-3883, 2010.

[50] H. Zegeye, "A hybrid iteration scheme for equilibrium problems, variational inequality problems and common fixed point problems in Banach spaces," Nonlinear Analysis: Theory, Methods E Applications, vol. 72, no. 3-4, pp. 2136-2146, 2010. 


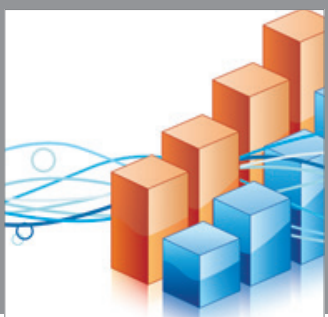

Advances in

Operations Research

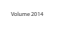

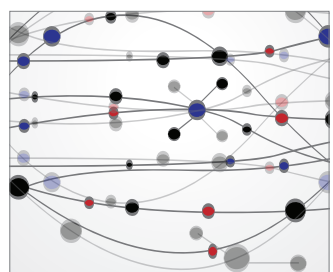

\section{The Scientific} World Journal
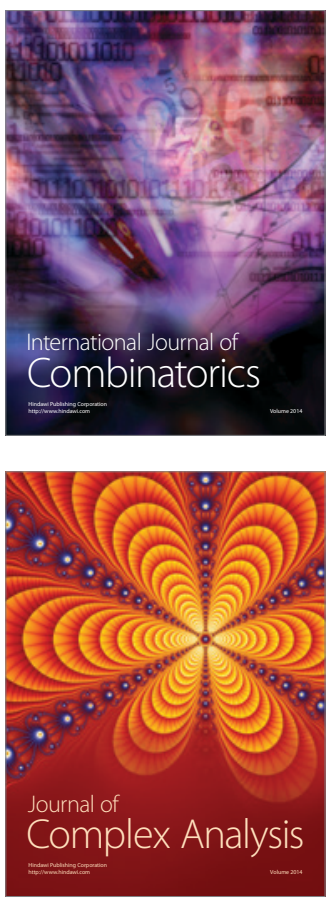

International Journal of

Mathematics and

Mathematical

Sciences
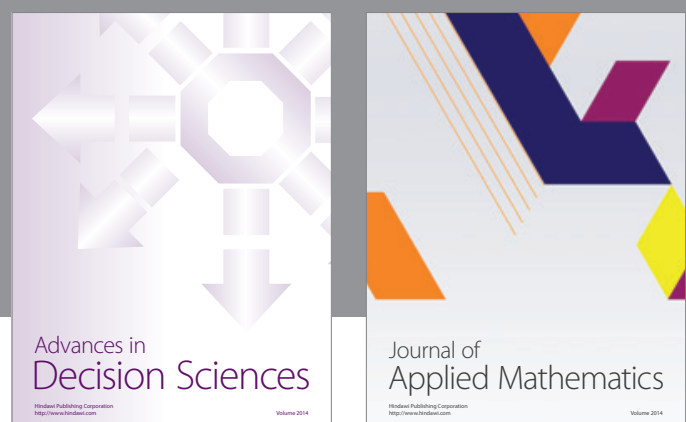

Journal of

Applied Mathematics
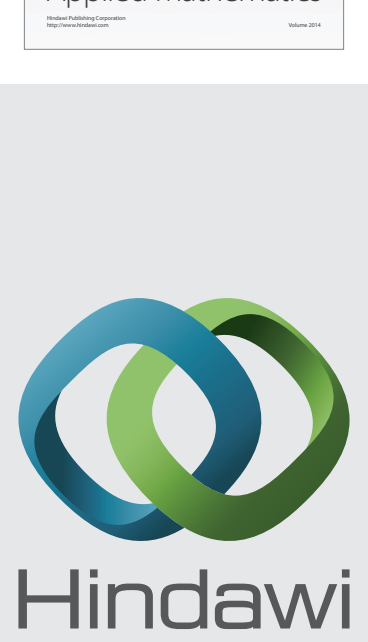

Submit your manuscripts at http://www.hindawi.com
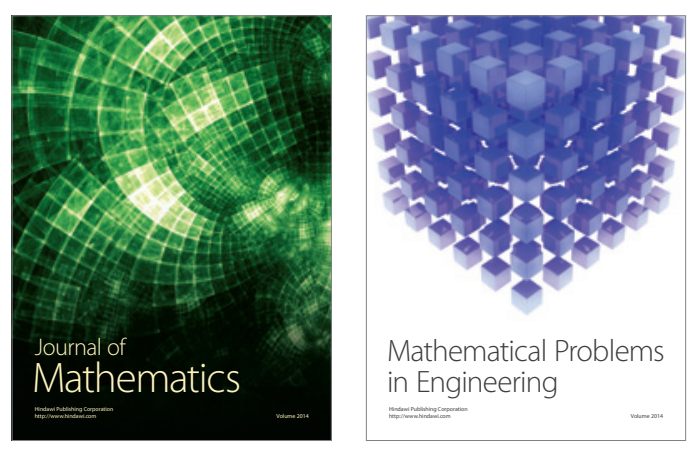

Mathematical Problems in Engineering
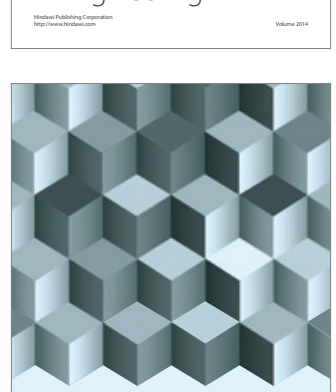

Journal of

Function Spaces
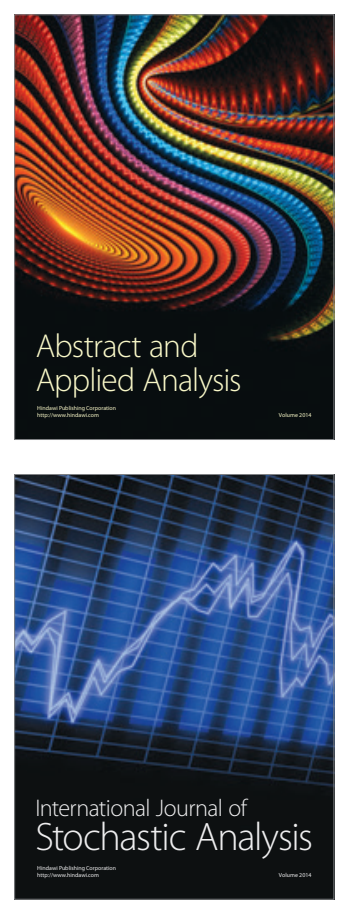

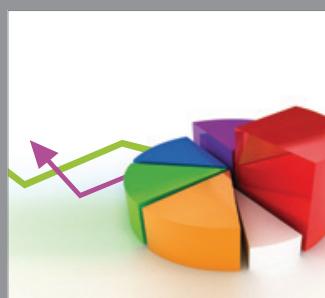

ournal of

Probability and Statistics

Promensencen
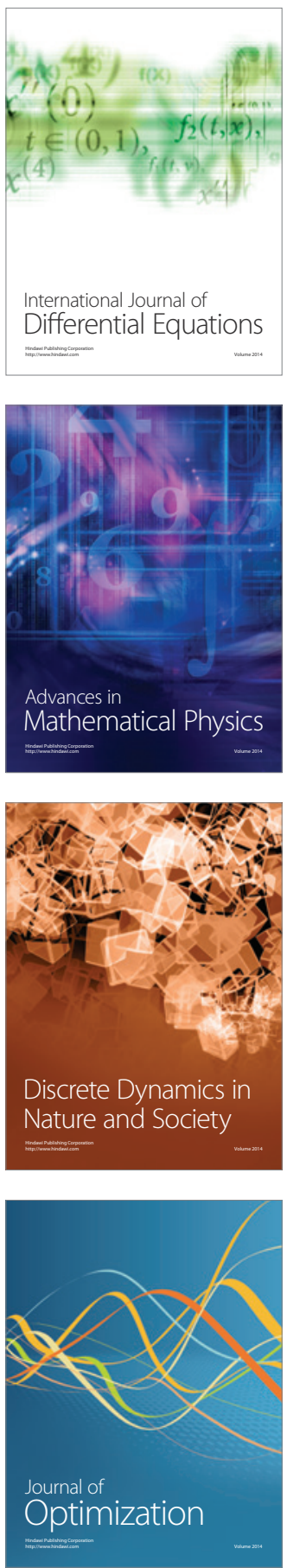